Research Journal of Applied Sciences 14 (4): 129-134, 2019

ISSN: $1815-932 \mathrm{X}$

(C) Medwell Journals, 2019

\title{
Analysis of the Temperature in Rectangular Profile with and without Internal Heat Generation
}

\author{
${ }^{1}$ Kastriot A. Buza, ${ }^{2}$ Risto V. Filkoski and ${ }^{1}$ Florent J. Bunjaku \\ ${ }^{1}$ Faculty of Education, University of Prishtina "Hasan Prishtina", 10000 Prishtina, Kosovo \\ ${ }^{2}$ Faculty of Mechanical Engineering, University "Sts Cyril and Methodius", \\ 1000 Skopje, North Macedonia
}

\begin{abstract}
This study presents the analysis of the temperature profile of the rectangular fin with uniform generating of the internal heat and without internal heat generating by taking in the base of the rectangular fin the constant temperature. Consequently, it is displayed also the comparison of the temperature field of the rectangular fin by the application of the analytical and numerical method. For different fin materials based on constant heat transfer coefficient are presented the comparison tabularly. Depending on the characteristic parameters $\mathrm{N}$ for different values of internal heat generation it is presented graphically and also analyzed the efficiency of fins. The results in the numerical solution of the fin models were obtained by using ANSYS Software
\end{abstract}

Key words: Fin, heat flux, geometrical parameters, rectangular profile, fin efficiency, application

\section{INTRODUCTION}

Substantial improvements in energy efficiency in many industrial fields can be achieved by employing more effective heat transfer surfaces. By used the fins elements between the hot surface and the surrounding air can be achieved the heat transfer enhancement more efficiently (Sahiti, 2015; Mabood et al., 2013 and Bunjaku et al., 2017). Kraus et al. (2002) have presented in detail mathematical models for the optimization of the finned systems for different profiles. Sobamowo (2017) has analyzed the dimensionless temperature for the rectangular profile depending on the dimensionless length for different values of the thermo-geometrical parameter and internal heat generation. At the same time the analysis of efficiency dependency was carried for thermo-geometrical parameters for different values for dimensionless heat transfer. Aziz and Bouaziz (2011) has as well analyzed the dimensionless temperature field dependant on the dimensionless length as well as the efficiency coefficient for different values of internal heat generation depending on the dimensionless parameter of the convection-conduction. Aziz and Fang (2010) presented the solutions for the temperature distribution of different profiles of longitudinal fins and provided the relationship between the dimensionless heat flux, the fin parameter and dimensionless tip temperature. Ghasemi et al. (2014) for the longitudinal fin with a temperature-dependent on thermal conductivity and internal heat generation have used the Differential Transformation Method (DTM) for solving the non-linear temperature distribution equation. Ganji and Dogonchi (2014) analyzed the temperature distribution in the rectangular profile and presented that by increasing thermo-geometric parameter that leads to a decrease in temperature distribution and by increasing thermal conductivity and heat generation gradient, temperature distribution increases. Fakir et al. (2013) analyzed the temperature distribution behavior in a fin and plate and presented the EFEM algorithm for the solution of one dimensional heat transfer problem for rectangular fin. Chikurde et al. (2018) presented the heat transfer during natural convection and comparing the plane fin and fins with perforations. Saraireh (2018) has presented of heat transfer rate for rectangular fin by the numerical method and results has compared with data obtained by the experimental method where are showed a very good agreement between two methods. Filkoski et al. (2016) have presented several case studies of analysis of different thermal systems with the application of the CFD technique, emphasizing its potential for research and for engineering educational purposes which is demonstrated with practical examples and interpretation of test results in connection to certain specific issues. Raju et al. (2017) have used ANSYS Software to analyze the temperature distribution and heat flux on different types of fins.

The current study provides an analysis of the temperature distribution through rectangular fin and the

Corresponding Author: Florent J. Bunjaku, Faculty of Education, University of Prishtina "Hasan Prishtina", 10000 Prishtina, Kosovo 
obtained results are compared by two methods analytical and numerical. Further, the researchers provided the fin efficiency by changing internal heat generation as a function of fin characteristic parameter $\mathrm{N}$.

\section{MATERIALS AND METHODS}

Analytical method: Very important for simplification and better accuracy of the solution of equations that define the fin geometries are the assumptions and constraints that are employed to define and limit the problem. The analysis of the different fin geometries in contemporary researches are based on the researches by Murray and Gardner which are almost always referred to as the Murray-Gardner assumptions and described by Kraus et al. (2002) research. The common assumptions are:

- The heat flow through the fin and its temperatures remain constant with time

- The fin material is homogeneous, its thermal conductivity is the same in all directions and it remains constant

- The convective heat transfer coefficient on the faces of the fin is constant and uniform over the entire surface of the fin

- The temperature of the medium surrounding the fin is uniform

- The fin thickness is small, compared to its height and length, so that, temperature gradients across the fin thickness and heat transfer from the edges of the fin may be neglected

- The temperature at the base of the fin is uniform

The comparison of the temperature along the fin through analytical and numerical methods will be carried for the fin with dimension $5 \times 50 \mathrm{~mm}$. The surface and the perimeter of the fin rectangular cut will be noted at the distance $x$ from the fin tip, respectively with $f_{z}$ and $P_{x}$ (Fig. 1).

Therefore, the thermal balance equation for the element $\mathrm{dx}$ of the fin can be displayed according to Fourier equation:

$$
\begin{aligned}
& Q_{x}=k \cdot f_{x} \cdot \frac{d \vartheta}{d x} \\
& d Q=Q_{x}+d x-Q_{x}=\frac{d}{d x}\left(k \cdot f_{x} \cdot \frac{d \vartheta}{d x}\right) \cdot d x
\end{aligned}
$$

where, $\theta=\mathrm{T}-\mathrm{T}_{\mathrm{s}}$, so that, $\theta$ is the respective temperature difference between the fin Temperature ( $\mathrm{T}$ ) and the temperature of the surrounding environment $\left(\mathrm{T}_{\mathrm{s}}\right)$.

The thermal flux that is exchanged between the fin and the surrounding air through convection is given as per:

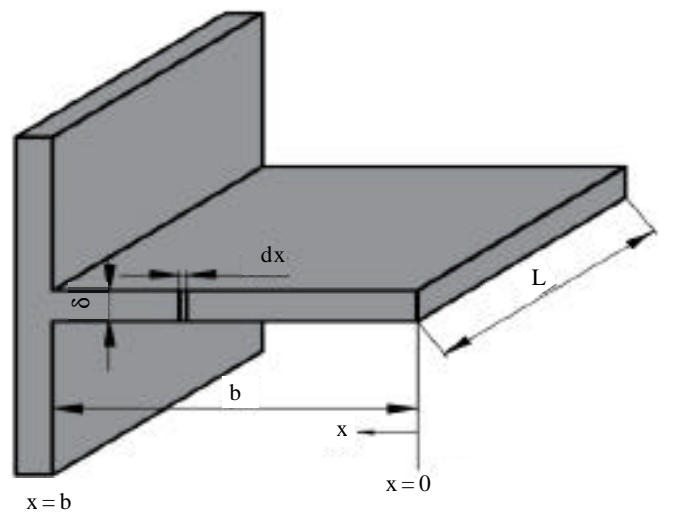

Fig. 1: The profile of rectangular fin

$$
\mathrm{dQ}=\mathrm{h} \cdot \mathrm{P}_{\mathrm{x}} \cdot \vartheta \cdot \mathrm{dl}
$$

For the element of the side surface of the fin the following serves:

$$
\mathrm{dl}=\sqrt{1+\left(\frac{1}{2} \cdot \frac{\mathrm{d} \delta}{\mathrm{dx}}\right)^{2}} \cdot \mathrm{dx}
$$

For thinner fins it can be taken the following:

$$
\frac{1}{2} \cdot \frac{\mathrm{d} \delta}{\mathrm{d} x} \leq 1
$$

According to Eq. 1 and 2 the following is valid:

$$
\frac{d}{d x}\left(\mathrm{k} \cdot \mathrm{f}_{\mathrm{x}} \cdot \frac{\mathrm{d} \vartheta}{\mathrm{dx}}\right)=\mathrm{h} \cdot \mathrm{P}_{\mathrm{x}} \cdot \vartheta
$$

In relation to the application of dimensionless parameter the following signs can be applied:

$$
\mathrm{X}=\mathrm{x} / \mathrm{b}, \tilde{\delta}_{\mathrm{x}}=\delta_{\mathrm{x}} / \delta_{0}, \theta=\vartheta / \vartheta_{0}
$$

The perimeter of the straight fin does not change, so that, the following can be taken $\mathrm{f}_{\mathrm{x}}=\mathrm{P} \cdot \boldsymbol{\delta}_{\mathrm{x}} / 2$ where according to Eq. 5 it can be written:

$$
\frac{d}{d x}\left(k \cdot f_{x} \cdot \frac{d \vartheta}{d x}\right)=h \cdot P_{x} \cdot \vartheta-q_{g} \cdot f_{x}
$$

where, $q_{g}$ is the specific thermal flux of the internal source of the heat. After replacing the above mentioned parameters and derivation, Eq. 6 can be displayed by:

$$
\frac{\mathrm{d}^{2} \theta}{\mathrm{dX}}=\mathrm{N}^{2} \cdot \theta-\frac{\mathrm{qg}_{\mathrm{g}} \cdot \mathrm{b}^{2}}{\mathrm{k} \cdot \vartheta_{0}}
$$




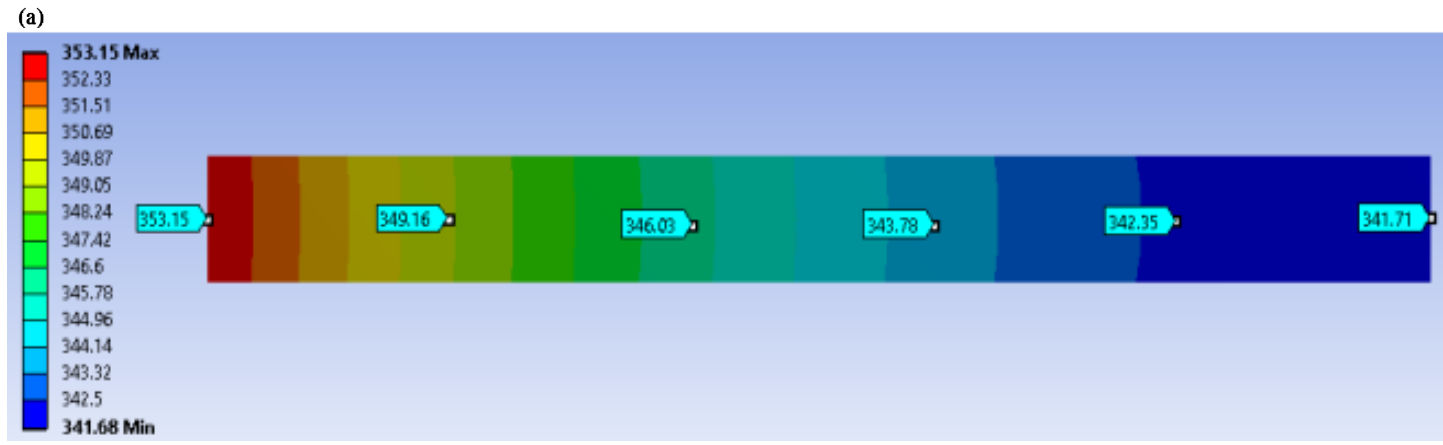

(b)

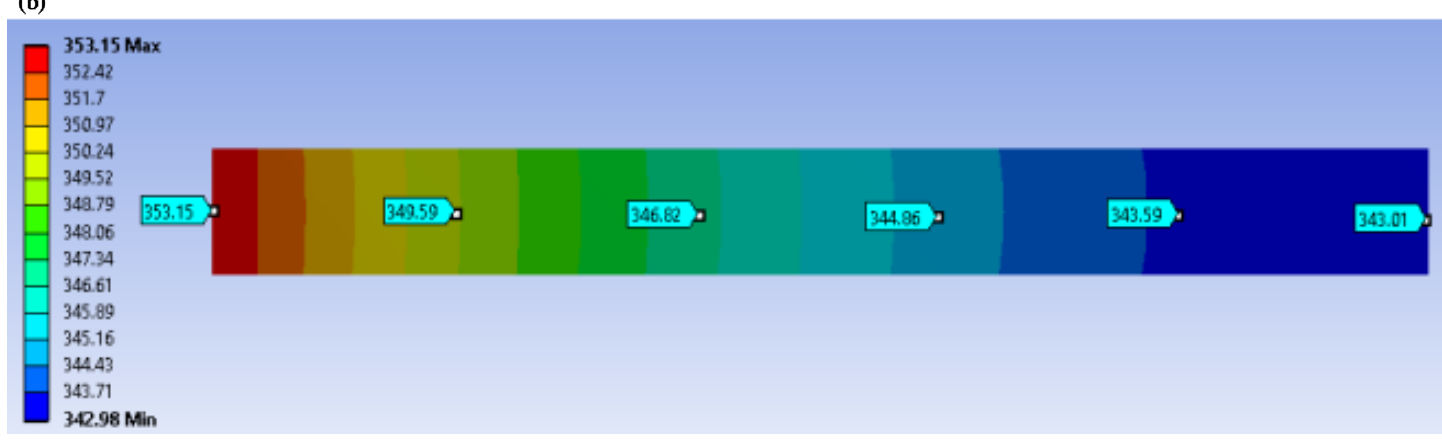

Fig. 2: a) Numerical prediction of temperature profile of rectangular fin of the steel material and b) With internal heat generation $\mathrm{q}_{\mathrm{g}}=75 \mathrm{~kW} / \mathrm{m}^{3}$

For boundary conditions:

$$
\begin{aligned}
& X=0, \quad \frac{d \theta}{d X}=0 \\
& X=1, \quad \theta=1
\end{aligned}
$$

The solution of differential Eq. 7 as per boundary conditions Eq. 8 it is gained the following:

$$
\theta=\left(1-\frac{q_{g} \cdot b^{2}}{k \cdot \vartheta_{0} \cdot N^{2}}\right) \cdot \frac{\cosh (N \cdot X)}{\cosh (N)}+\frac{q_{g} \cdot b^{2}}{k \cdot \vartheta_{0} \cdot N^{2}}
$$

Where we have:

$$
\theta=\frac{T-T_{s}}{T_{b}-T_{s}} \text { and } N^{2}=\frac{2 h}{k \delta} \cdot b^{2}
$$

Equation 9 can be displayed as:

$$
T_{g}=T_{s}+\left(T_{b}-T_{s}\right)\left[\begin{array}{l}
\left(\begin{array}{l}
1-\frac{q_{g} \cdot b^{2}}{k \cdot \vartheta_{0} \cdot N^{2}}
\end{array}\right) \cdot \frac{\cosh (N)}{\cosh (N \cdot X)}+ \\
\frac{q_{g} \cdot b^{2}}{k \cdot \vartheta_{0} \cdot N^{2}}
\end{array}\right]
$$

If there is no internal heat source inside the finned system then $\mathrm{q}_{\mathrm{g}}=0$ and according to Eq. 9 the following is obtained:

$$
\mathrm{T}=\mathrm{T}_{\mathrm{s}}+\left(\mathrm{T}_{\mathrm{b}}-\mathrm{T}_{\mathrm{s}}\right)\left(\frac{\cosh (\mathrm{N})}{\cosh (\mathrm{N} \cdot \mathrm{X})}\right)
$$

Numerical method: Concerning the analysis of the respective model for the numerical method is used the ANSYS Software package steady state where initially the model of the fin with respective dimensions is created. At the following figure the finned models are presented for the steel material for the case with and without internal heat generating.

The gained results with analytical and numerical method with and without internal heat source are presented in the following table.

Based on the data presented at Table 1, through numerical and analytical method in the following Fig. 2 is presented the temperature along the fin in the function of length whereas it can be noticed that there is a discrepancy. This difference is because in the numerical method there is a heat transfer even at the fin tip whereby in the analytical method this heat transfer is neglected. At the same time in the numerical method the model solution is three-dimensional while in the analytical method the solution is one-dimensional (Fig. 3). 
Res. J. Applied Sci., 14 (4): 129-134, 2019

Table 1: Analytical and numerical values of the temperature for rectangular fins for steel material

\begin{tabular}{|c|c|c|c|c|c|c|c|c|c|c|}
\hline \multirow{3}{*}{$\begin{array}{l}\text { Rect. fin } \\
\text { Height } \\
\text { of fin (m) }\end{array}$} & \multicolumn{10}{|c|}{ Steel materials $\mathrm{k}=60.5 \mathrm{~W} /(\mathrm{mk})$ and $\mathrm{h}=25 \mathrm{~W} /\left(\mathrm{m}^{2} \mathrm{k}\right)$} \\
\hline & \multicolumn{5}{|c|}{$\mathrm{q}_{\mathrm{g}}=0\left(\mathrm{~kW} / \mathrm{m}^{3}\right)(\mathrm{K})$} & \multicolumn{5}{|c|}{$\mathrm{q}_{\mathrm{g}}=75\left(\mathrm{~kW} / \mathrm{m}^{3}\right)(\mathrm{K})$} \\
\hline & $T_{A}$ & $\mathrm{~T}_{\mathrm{N1}}$ & $\mathrm{T}_{\mathrm{N} 2}$ & $\mathrm{~T}_{\mathrm{N1}}-\mathrm{T}_{\mathrm{A}}$ & $\mathrm{T}_{\mathrm{A}}-\mathrm{T}_{\mathrm{N} 2}$ & $\mathrm{~T}_{\mathrm{A}}$ & $\mathrm{T}_{\mathrm{N1}}$ & $\mathrm{T}_{\mathrm{N} 2}$ & $\mathrm{~T}_{\mathrm{N} 1}-\mathrm{T}_{\mathrm{A}}$ & $\mathrm{T}_{\mathrm{B}}-\mathrm{T}_{\mathrm{N} 2}$ \\
\hline 0 & 342.58 & 342.59 & 341.71 & 0.01 & 0.87 & 343.90 & 343.91 & 343.01 & 0.01 & 0.89 \\
\hline 0.01 & 342.99 & 343.03 & 342.35 & 0.04 & 0.64 & 344.26 & 344.29 & 343.59 & 0.03 & 0.67 \\
\hline 0.02 & 344.22 & 344.28 & 343.78 & 0.06 & 0.44 & 345.34 & 345.39 & 344.86 & 0.05 & 0.48 \\
\hline 0.03 & 346.30 & 346.36 & 346.03 & 0.06 & 0.27 & 347.16 & 347.21 & 346.82 & 0.05 & 0.34 \\
\hline 0.04 & 349.26 & 349.30 & 349.16 & 0.04 & 0.1 & 349.75 & 349.76 & 349.59 & 0.01 & 0.16 \\
\hline 0.05 & 353.15 & 353.15 & 353.15 & 0 & 0 & 353.15 & 353.15 & 353.15 & 0 & 0 \\
\hline
\end{tabular}

Table 2: Analytical and numerical values of the temperature for rectangular fins for aluminum material

Rect. fin Aluminum materials $\mathrm{k}=202.4 \mathrm{~W} /(\mathrm{mk})$ and $\mathrm{h}=25 \mathrm{~W} /\left(\mathrm{m}^{2} \mathrm{k}\right)$

\begin{tabular}{|c|c|c|c|c|c|c|c|c|c|c|}
\hline \multirow{2}{*}{$\begin{array}{l}\text { Height } \\
\text { of fin (m) }\end{array}$} & \multicolumn{5}{|c|}{$\mathrm{q}_{\mathrm{g}}=0\left(\mathrm{~kW} / \mathrm{m}^{3}\right)(\mathrm{K})$} & \multicolumn{5}{|c|}{$\mathrm{q}_{\mathrm{g}}=75\left(\mathrm{~kW} / \mathrm{m}^{3}\right)(\mathrm{K})$} \\
\hline & $T_{A}$ & $\mathrm{~T}_{\mathrm{N1}}$ & $\mathrm{T}_{\mathrm{N} 2}$ & $\mathrm{~T}_{\mathrm{N1}}-\mathrm{T}_{\mathrm{A}}$ & $\mathrm{T}_{\mathrm{A}}-\mathrm{T}_{\mathrm{N} 2}$ & $\mathrm{~T}_{\mathrm{A}}$ & $\mathrm{T}_{\mathrm{N1}}$ & $\mathrm{T}_{\mathrm{N} 2}$ & $\mathrm{~T}_{\mathrm{N1}}-\mathrm{T}_{\mathrm{A}}$ & $\mathrm{T}_{\mathrm{A}}-\mathrm{T}_{\mathrm{N} 2}$ \\
\hline 0.00 & 349.63 & 349.63 & 349.30 & 0 & 0.33 & 350.06 & 350.07 & 349.73 & 0.01 & 0.33 \\
\hline 0.01 & 349.77 & 349.77 & 349.51 & 0 & 0.26 & 350.19 & 350.20 & 349.93 & 0.01 & 0.26 \\
\hline 0.02 & 350.19 & 350.20 & 350.00 & 0.01 & 0.19 & 350.55 & 350.56 & 350.37 & 0.01 & 0.18 \\
\hline 0.03 & 350.89 & 350.90 & 350.77 & 0.01 & 0.12 & 351.16 & 351.17 & 351.05 & 0.01 & 0.11 \\
\hline 0.04 & 351.87 & 351.89 & 351.83 & 0.02 & 0.04 & 352.03 & 352.04 & 351.98 & 0.01 & 0.05 \\
\hline 0.05 & 353.15 & 353.15 & 353.15 & 0 & 0 & 353.15 & 353.15 & 353.15 & 0 & 0 \\
\hline
\end{tabular}

Table 3: Analytical and numerical values of the temperature for rectangular fins for cooper material

\begin{tabular}{|c|c|c|c|c|c|c|c|c|c|c|}
\hline \multirow{3}{*}{$\begin{array}{l}\text { Rect. fin } \\
\text { Height } \\
\text { of fin (m) }\end{array}$} & \multicolumn{10}{|c|}{ Copper materials $\mathrm{k}=387.6 \mathrm{~W} /(\mathrm{mk})$ and $\mathrm{h}=25 \mathrm{~W} /\left(\mathrm{m}^{2} \mathrm{k}\right)$} \\
\hline & \multicolumn{5}{|c|}{$\mathrm{q}_{\mathrm{g}}=0\left(\mathrm{~kW} / \mathrm{m}^{3}\right)(\mathrm{K})$} & \multicolumn{5}{|c|}{$\mathrm{q}_{\mathrm{g}}=75\left(\mathrm{~kW} / \mathrm{m}^{3}\right)(\mathrm{K})$} \\
\hline & $\mathrm{T}_{\mathrm{A}}$ & $\mathrm{T}_{\mathrm{N1}}$ & $\mathrm{T}_{\mathrm{N} 2}$ & $\mathrm{~T}_{\mathrm{N} 1}-\mathrm{T}_{\mathrm{A}}$ & $\mathrm{T}_{\mathrm{B}}-\mathrm{T}_{\mathrm{N} 2}$ & $\mathrm{~T}_{\mathrm{A}}$ & $\mathrm{T}_{\mathrm{N} 1}$ & $\mathrm{~T}_{\mathrm{N} 2}$ & $\mathrm{~T}_{\mathrm{N} 1}-\mathrm{T}_{\mathrm{A}}$ & $\mathrm{T}_{\mathrm{B}}-\mathrm{T}_{\mathrm{N} 2}$ \\
\hline 0.00 & 351.26 & 351.27 & 351.08 & 0.01 & 0.18 & 351.50 & 351.51 & 350.32 & 0.01 & 1.18 \\
\hline 0.01 & 351.34 & 351.35 & 351.20 & 0.01 & 0.14 & 351.56 & 351.57 & 351.43 & 0.01 & 0.13 \\
\hline 0.02 & 351.56 & 351.57 & 351.46 & 0.01 & 0.1 & 351.76 & 351.77 & 351.67 & 0.01 & 0.09 \\
\hline 0.03 & 351.94 & 351.95 & 351.87 & 0.01 & 0.07 & 352.09 & 352.10 & 352.04 & 0.01 & 0.05 \\
\hline 0.04 & 352.47 & 352.48 & 352.44 & 0.01 & 0.03 & 352.55 & 352.56 & 352.53 & 0.01 & 0.02 \\
\hline 0.05 & 353.15 & 353.15 & 353.15 & 0.00 & 0.00 & 353.15 & 353.15 & 353.15 & 0.00 & 0.00 \\
\hline
\end{tabular}

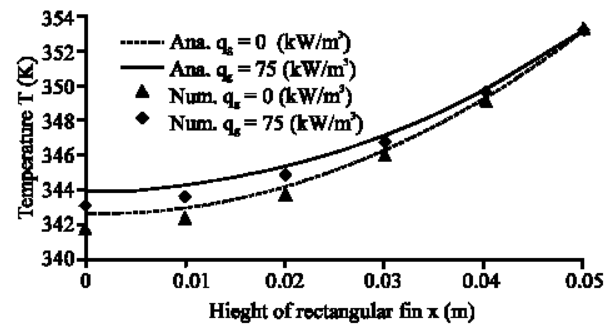

Fig. 3: Temperature profile through rectangular fin

From the above presented data for the steel material, through the same method the analysis continued by changing the material to aluminium and copper. These data are displayed at the following tables whereby in these cases also there are small discrepancies for the same reasons mentioned above (Table 2 ).

From the data presented in Table 3 it can be seen that in all the cases there is a temperature change in analytical and numerical methods where this change is more stressed between realistic analytical and numerical method.

\section{RESULTS AND DISCUSSION}

Efficiency of the rectangular fin: The thermal flux exchanged at the base of the fin is:

$$
\mathrm{Q}=\left.\mathrm{k} \cdot \delta \cdot \frac{\mathrm{d} \vartheta}{\mathrm{dx}}\right|_{\mathrm{x}=\mathrm{b}}=\vartheta_{0} \sqrt{2 \mathrm{hk} \delta}\left(1-\tilde{\mathrm{q}}_{\mathrm{g}}\right) \tanh (\mathrm{N})
$$

where by according to the dimensional analysis the following sign is given:

$$
\tilde{\mathrm{q}}_{\mathrm{g}}=\frac{\mathrm{q}_{\mathrm{g}} \cdot \mathrm{b}^{2}}{\mathrm{k} \cdot \vartheta_{0} \cdot \mathrm{N}^{2}}=\frac{\mathrm{q}_{\mathrm{g}} \cdot \delta}{2 \cdot \mathrm{k} \cdot \vartheta_{0}}
$$

For the fin efficiency of the finned system with internal heat source there is:

$$
\eta=\frac{\mathrm{Q}}{2 \mathrm{hb} \vartheta_{0}}=\frac{\tanh (\mathrm{N})}{\mathrm{N}} \cdot\left(1-\tilde{\mathrm{q}}_{\mathrm{g}}\right)
$$

The efficiency of the fin where there is no internal heat source is: 


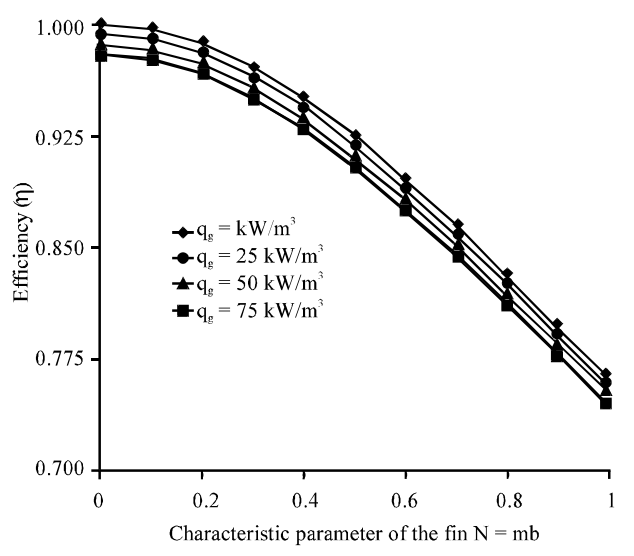

Fig. 4: Ratio of the internal energy and the characteristic parameter $\mathrm{N}$

$$
\eta=\frac{\tanh (\mathrm{N})}{\mathrm{N}}
$$

From the above presented Fig. 4 it can be seen that by increasing the internal energy and the characteristic parameter $\mathrm{N}$ the efficiency is decreased. This decrease is stressed more by the increase of characteristic number $\mathrm{N}$.

\section{CONCLUSION}

This study presents in analytical and numerical methods the comparison of the rectangular fin temperature by internal heat generation and without internal generation. For the rectangular fin model with internal heat generation, the temperature field is higher than in the case where there is no internal heat generation. This change of temperature field is more stressed by increasing the fin length. By numerical methods are analyzed the cases by adjusting the boundary conditions solved by the analytical method, i.e., by eliminated the heat transfer at the top of the fin and also the case where there is transfer at the top of the fin. From the obtained results which presented in the above tables it can be remark that there is a discrepancy between the two methods. This is because for the analytical solution the problem is considered to be one-dimensional while in the numerical solution are applied the three-dimensional models.

By increasing the internal energy, the efficiency of the rectangular fin is decreased whereas by increasing the characteristic parameter $\mathrm{N}$ the efficiency decrease is evident. The comparison of the temperature profile by two methods and the fin efficiency for different values of internal heat generation are convenient for use by engineers dealing with the design and analysis of heat generating fins.

\section{NOMENCLATURE}

h Heat transfer coefficient $\left(\mathrm{W} /\left(\mathrm{m}^{2} \mathrm{~K}\right)\right)$

b Fin height $(\mathrm{m})$

$\mathrm{k}$ Thermal conductivity $(\mathrm{W} /(\mathrm{mK}))$

L Fin length (m)

$\mathrm{m} \quad$ Fin performance parameter $\left(\mathrm{m}^{-1}\right)$

$\mathrm{q}_{\mathrm{g}}$ Internal rate of heat generation $\left(\mathrm{W} / \mathrm{m}^{3}\right)$

$\tilde{\mathrm{q}}_{\mathrm{g}} \quad$ Generation number, dimensionless

$\mathrm{N}$ Characteristic parameters of the fin

$\mathrm{P} \quad$ Fin perimeter $(\mathrm{m})$

$\mathrm{T}$ Temperature $(\mathrm{K})$

\section{Greek symbols}

$\delta \quad$ Fin thickness ( $\mathrm{m}$ )

$\theta \quad$ Dimensionless temperature

$\eta \quad$ Fin efficiency

\section{Subscripts}

b Base of fin

s Surrounding air

A Analytical method

$\mathrm{N}_{1}$ Ideal numerical method

$\mathrm{N}_{2}$ Real numerical method

\section{REFERENCES}

Aziz, A. and M.N. Bouaziz, 2011. A least squares method for a longitudinal fin with temperature dependent internal heat generation and thermal conductivity. Energy Convers. Manage., 52: 28762882.

Aziz, A. and T. Fang, 2010. Alternative solutions for longitudinal fins of rectangular, trapezoidal and concave parabolic profiles. Energy Convers. Manage., 51: 2188-2194.

Bunjaku, F., R.V. Filkoski and N. Sahiti, 2017. Thermal optimization and comparison of geometric parameters of rectangular and triangular fins with constant surfacing. Strojniski Vestnik J. Mech. Eng., 63: 439-446.

Chikurde, R.C., B.S. Kothavale, N.K. Sane and S.V. Dingare, 2018. Convection heat transfer studies on rectangular fin arrays with different surface roughness, perforations or protrusions on fins-a review. Intl. Rev. Mech. Eng., 12: 97-106.

Fakir, M., S. Khatun and S.B. Basri, 2013. Enhancement of algorithm and investigation of heat transfer through fins. Intl. Rev. Mech. Eng., 7: 1037-1043. 
Filkoski, R.V., M. Cekerovska and F. Bunjaku, 2016. Research and education in thermal and power engineering with support of CFD technology. Proceedings of the 6th REMOO-2016 International Conference and Workshop on Science and Engineering for Reliable Energy, May 18-20, 2016, Budva, Montenegro, pp: nnn.1-nnn.12.

Ganji, D.D. and A.S. Dogonchi, 2014. Analytical investigation of convective heat transfer of a longitudinal fin with temperature-dependent thermal conductivity, heat transfer coefficient and heat generation. Intl. J. Phys. Sci., 9: 466-474.

Ghasemi, S.E., M. Hatami and D.D. Ganji, 2014. Thermal analysis of convective fin with temperature-dependent thermal conductivity and heat generation. Case Stud. Therm. Eng., 4: 1-8.

Kraus, A.D., A. Aziz and J. Welty, 2002. Extended Surface Heat Transfer. John Wiley and Sons, Hoboken, New Jersey, USA., ISBN:9780471436638, Pages: 1120.
Mabood, F., W.A. Khan and A.I.M. Ismail, 2013. Series solution for steady heat transfer in a heat-generating fin with convection and radiation. Math. Prob. Eng., 2013: 1-7.

Raju, V.N., P. Sivakumar, K.L. Narayana, A. Srujan and K. Mallikarjun et al., 2017. Steady state thermal analysis of heat sink with fins of different geometry. Intl. J. Mech. Eng. Technol., 8: 196-206.

Sahiti, N., 2015. Interrelation between pin length and heat exchanger performance. Appl. Therm. Eng., 91: 946-952.

Saraireh, M.A., 2018. Natural convection heat transfer from extended surfaces on vertical base. J. Eng. Appl. Sci., 13: 7298-7301.

Sobamowo, M.G., 2017. Analysis of convective longitudinal fin with temperature-dependent thermal conductivity and internal heat generation. Alexandria Eng. J., 56: 1-11. 